\title{
Excess of non-verbal cases of autism spectrum disorders presenting to orthodox clinical practice in Africa - a trend possibly resulting from late diagnosis and intervention
}

Muideen O Bakare, MB BS, FMCPsych, MNIM

Child and Adolescent Unit, Federal Neuropsychiatric Hospital, New Haven, Enugu, Nigeria, and Childhood Neuropsychiatric Disorders Initiatives, Nigeria

Kerim M Munir, MD, MPH, DSC

University Center for Excellence in Developmental Disabilities (UCEDD), Division of Developmental Medicine, Children's Hospital and Harvard Medical School, Boston, Massachusetts, USA

Objectives. Characteristics of children with autism spectrum disorders (ASDs) in Africa are not known because of unavailability of large-scale epidemiological studies in this region. This review explored the age at first presentation to orthodox clinical practice of African children with ASDs and their expressive language ability at presentation.

Methods. A literature search of case series and case reports of ASDs from Africa was done through PubMed/MEDLINE, Google Scholar, African Journals Online (AJOL), and archives of the Nigerian Journal of Psychiatry. Six articles included content relating to age of the child at first presentation to orthodox clinical practice and symptoms at presentation related to expressive language ability and therefore fulfilled the inclusion criteria. Suggestions are made to explain the observations emanating from the review.

Results. An excess of non-verbal over verbal cases of ASDs have been presenting to orthodox clinical practice and there is a common denominator of late presentation/diagnosis and in turn late intervention, with most cases presenting for the first time well above 8 years of age. Attempts to explain these observations included low levels of knowledge and awareness about ASDs in Africa; problems with help-seeking behaviour; and lack of mental healthcare facilities and trained personnel.

Conclusions. Enhancement of processes directed at ensuring early diagnosis and interventions, especially interventions aimed at improving speech and language development well and sufficiently early, may bring about a shift in the trend of excess non-verbal cases of ASDs over verbal cases presenting to orthodox clinical practice.
Many aspects of autism spectrum disorders (ASDs), including characteristics of African children with ASDs, are not known because of non-availability of large-scale epidemiological studies. For example, the average age at first presentation of African children with ASDs to orthodox clinical practice and their symptoms at presentation relating to expressive language ability, have not been examined. This review examined these two parameters.

\section{Methods}

A literature search of case series and case reports of ASDs from the African continent was done through PubMed/MEDLINE, Google Scholar, African Journals Online (AJOL), and archives of the Nigerian Journal of Psychiatry. Six articles included content related to age and symptoms related to expressive language ability at the time of first presentation to orthodox clinical practice and therefore met the inclusion criteria. Of the 6 studies that met the inclusion criteria, 1 was from Tunisia, 1 from Tanzania, 1 from Kenya and 3 from Nigeria. Attempts were made to explain the observations emanating from review of these articles. The suggestions made were then discussed.

\section{Results}

Although few studies from Africa met the inclusion criteria, these case series and case reports of ASDs revealed an excess of nonverbal over verbal cases presenting to orthodox clinical practice. ${ }^{1-6}$ In addition, a common denominator of this observation was late presentation/diagnosis of cases reported, with most patients well above 8 years of age. ${ }^{1 \cdot 6}$ Belhadj et al. ${ }^{1}$ reported that $51.2 \%$ of cases of ASDs in a series they studied in their clinic in Tunisia were nonverbal. Similarly, Mankoski et al. ${ }^{2}$ in a case series from Tanzania observed that about $71 \%$ of patients they saw in their clinic were non-verbal.

In reports of ASDs from Africa, patients often fail to develop expressive language ability, with little or no speech at all. This trend was observed in Kenya by Dhadphale et al. Onuora ${ }^{3}$ reported a case of ASD in a 15-year-old Nigerian boy from south-eastern Nigeria. The boy tended to be mute with little or no speech and was being seen for the first time at the age of 15 years in a psychiatric clinic of a university teaching hospital. More recently in south-eastern Nigeria, Bakare and Ikegwuonu ${ }^{5}$ reported a case of a 13-year-old boy with co-morbid ASD and oculocutaneous albinism. This case was also characterised by lack of expressive language, with little or no speech, and the boy was being seen in an orthodox clinical practice for the first time at the age of 13 years. ${ }^{5}$ In south-western Nigeria, 
Bello-Mojeed et al. ${ }^{6}$ reported 2 cases of ASDs. The first was a boy who was being seen for the first time in orthodox clinical practice at the age of 17 years, and the second a girl being seen for the first time at the age of 14 . Both patients were unable to develop expressive language and manifested little or no speech. ${ }^{6}$

These cases of ASDs from Africa indicate that lack of expressive language ability and late age of presentation to orthodox clinical practice are common observations. Possible reasons for this trend may stem from a low level of knowledge and awareness about ASDs in Africa; late presentation to orthodox medical care, often complicated by a tortuous help-seeking pathway; unavailability of early educational and behavioural interventions even if a problem was identified; and inadequate mental healthcare facilities and trained personnel relative to the number of children in Africa.

\section{Discussion \\ Knowledge and awareness about ASDs in Africa}

Many studies in Nigeria have indicated low levels of knowledge and awareness about ASDs in Africa, which compromise early recognition and intervention. ${ }^{711}$ The African Network for the Prevention and Protection against Child Abuse and Neglect (ANPPCAN), Nigeria chapter, in a World Bank-sponsored programme carried out a survey to determine the level of knowledge and awareness of ASDs among healthcare workers and the general public in Enugu, south-eastern Nigeria.' The findings showed that there is a very low level of knowledge and awareness among the general populace and a low to average level among various categories of healthcare workers, with the level being highest in healthcare workers in psychiatric facilities. Using the template of findings and observations made during the ANPPCAN study, a standard questionnaire for assessing knowledge of healthcare workers about ASDs, aimed at early recognition, was designed and validated. ${ }^{8}$ A subsequent study consistently showed the same trend of low level of knowledge and awareness among healthcare workers. ${ }^{9}$ It was further observed that the ability of healthcare workers in psychiatric facilities to recognise symptoms of ASDs was better than that of their counterparts in paediatric units/departments. ${ }^{9}$ This does not bode well for early identification of ASDs in primary care settings, and the situation is perhaps analogous to that in developed countries, a decade or more earlier, when more severe and stigmaprone cases of ASDs were likely to present in psychiatric settings. Igwe et al. ${ }^{10}$ examined the level of knowledge about ASDs among healthcare workers undergoing training, comparing final-year medical, nursing and psychology students at the University of Nigeria in Enugu State, south-eastern Nigeria. Medical students were most likely to recognise symptoms of ASDs, followed by nursing and then psychology students. Overall, however, the level of knowledge of symptoms of ASDs was low in the three groups. ${ }^{10}$ Igwe et al." then examined knowledge of specialist paediatric and psychiatric nurses in Ebonyi State, also in south-eastern
Nigeria, establishing the same trend of a low level of knowledge. They found an association between improved knowledge and previous experience of participating in management of children with ASDs and also noted that specialist psychiatric nurses were slightly better able to recognise symptoms of ASDs than specialist paediatric nurses."

The available literature on knowledge about ASDs in Africa comes mainly from Nigeria. While caution must be exercised in generalising these findings, it is probable that the situation is similar in other sub-Saharan African countries.

The need for education of healthcare workers and the general public in Africa on ASDs cannot be ignored. Education would enhance early recognition and intervention, which has been observed to improve prognosis in individuals with ASDs.

\section{Late presentation to orthodox medical care, often complicated by a tortuous help-seeking pathway}

Bakare et al.' ${ }^{12}$ surveyed opinions of healthcare workers in southeastern Nigeria on causes of ASDs, finding that significant proportions of $14.2 \%$ and $26.9 \%$ subscribed to preternatural and supernatural aetiological explanations, respectively. Trends among healthcare workers ${ }^{12}$ typically reflect trends among the majority of the general African population. ${ }^{13}$ The preternatural and supernatural aetiological explanations for ASDs in this study ${ }^{12}$ bear out the spiritual beliefs of Africans in relation to causes of neuropsychiatric disorders in general. ${ }^{13}$ Such explanations for neuropsychiatric disorders often negatively influence help-seeking behaviour, ${ }^{13}$ help generally first being sought from spiritualists, traditional healers and other non-orthodox practices. ${ }^{13}$ This pattern of behaviour invariably results in delayed presentation to orthodox clinical practice, which is a common observation among African children with ASDs. $^{3.6}$ Late presentation of these children to orthodox medical care is also often accompanied by lack of expressive language ability $^{1-6}$ and denies affected children the opportunity for early intervention, especially interventions aimed at improving speech and language development.

\section{Inadequate mental healthcare facilities and trained personnel}

Child and adolescent psychiatry facilities in Africa are limited ${ }^{1416}$ and do not meet the needs of the paediatric population. Njenga ${ }^{17}$ noted that numbers of personnel such as psychiatrists, clinical psychologists and psychiatric nurses, among others, are inadequate for mental health needs relative to the African population. A study of opinions of healthcare workers on availability of facilities and laws supporting the needs and rights of children with ASDs and other developmental disorders in Nigeria also revealed inadequate facilities and personnel. ${ }^{9}$ The study ${ }^{9}$ showed that despite two United Nations Conventions, that on the Rights of the Child and on the Rights of Persons with Disabilities, child rights are not supported by 
law in every state of the country, and where there are laws they are poorly implemented. There is therefore a need to reach out to the general community and community healthcare workers to raise awareness about childhood neuropsychiatric disorders, which are not often recognised early.

While observations in the available literature are highlighted in this review, it is important to emphasise that there is currently a paucity of literature addressing the issues of age at first presentation to orthodox clinical practice and symptoms related to expressive language ability of African children with ASDs.

\section{Conclusions}

This article proposes that the excess of non-verbal over verbal cases of ASDs presenting to orthodox clinical practice observed in Africa is probably due to poor knowledge and awareness about ASDs, inappropriate help-seeking behaviour, and inadequate child and adolescent psychiatric facilities and trained healthcare personnel. Improvements in these areas may change the currently observed trend because they would promote early recognition, diagnosis and interventions, especially interventions directed at improving speech and language development well and sufficiently early. Epidemiological studies are urgently needed to examine the characteristics of children with ASDs in Africa. For example, among other things it will be useful to examine whether decreasing language and cognitive scores among children with ASDs in Africa also leads to a decreasing male/female ratio, as has been reported in epidemiological studies in a developed country context. ${ }^{18}$

Competing interests. The authors declare that there are no competing interests.

Acknowledgements. This work was supported in part by the Fogarty International Center/NIH Mental Health \& Developmental Disabilities (MH/DD) Program at the Children's Hospital, Boston, Harvard Medical School (grant award no. D43 TW0005807, PI: K. Munir).

\section{References}

1. Belhadj A, Mrad R, Halayem MB. A clinic and paraclinic study of Tunisian population of children with autism. About 63 cases. Tunis Med 2006;84(12):763-767.

2. Mankoski RE, Collins M, Ndosi NK, et al. Etiologies of autism in a case-series from Tanzania. Autism Dev Disord 2006;36(8):1039-1051.

3. Dhadphale M, Lukwago MG, Gajjar M. Infantile autism in Kenya. Indian J Pediatr 1982; 49(396): 145-148.

4. Onuora AN. Infantile autism: a case report. Nigerian Journal of Psychiatry 1992;1 (3):169-171

5. Bakare MO, Ikegwuonu NN. Childhood autism in a 13 year old boy with oculocutaneous albinism: a case report. Journal of Medical Case Reports 2008;2:56. www. jmedicalcasereports.com/content/2/1/56 (accessed 9 November 2011).

6. Bello-Mojeed MA, Ogun OC, Omigbodun OO, Adewuya AO, Ladapo, HTO. Late identification of autistic disorder in Nigeria: an illustration with 2 case reports. Nigerian Journal of Psychiatry 2010/2011;9(2):31-35.

7. African Network for the Prevention and Protection against Child Abuse and Neglect (ANPPCAN), Nigeria Chapter. Communiqué on a Project to Increase the Level of Awareness on Autism and Develop a Mechanism for Care and Support of Children with Autism in Enugu State, South-Eastern Nigeria. ANPPCAN, 2007

8. Bakare MO, Ebigbo PO, Agomoh AO, Menkiti NC. Knowledge about childhood autism among health workers (KCAHW) questionnaire: description, reliability and internal consistency. Clinical Practice and Epidemiology in Mental Health 2008;4:17. www. cpementalhealth.com/content/4/1/17 (accessed 9 November 2011).

9. Bakare MO, Ebigbo PO, Agomoh AO, et al. Knowledge about childhood autism and opinion among healthcare workers on availability of facilities and law caring for needs and rights of children with childhood autism and other developmental disorders in Nigeria. BMC Pediatr 2009;9:12. http://www.biomedcentral.com/1471-2431/9/12 (accessed 9 November 2011).

10. Igwe MN, Bakare MO, Agomoh AO, Onyeama GM, Okonkwo KO. Factors influencing knowledge about childhood autism among final year undergraduate medical, nursing and psychology students of University of Nigeria, Enugu State, Nigeria. Ital J Pediatr 2010;36:44. http://www.ijponline.net/content/36/1/44 (accessed 9 November 2011).

11. Igwe MN, Ahanotu AC, Bakare MO, Achor JU, Igwe C. Assessment of knowledge about childhood autism among paediatric and psychiatric nurses in Ebonyi State, Nigeria. Child and Adolescent Psychiatry and Mental Health 2011;5(1):1. http://www.capmh.com/ content/5/1/1 (accessed 9 November 2011).

12. Bakare MO, Agomoh AO, Ebigbo PO, et al. Etiological explanation, treat-ability and preventability of childhood autism: a survey of Nigerian healthcare workers' opinion. Ann Gen Psychiatry 2009;8:6. http://www.annals-general-psychiatry.com/content/8/1/6 (accessed 9 November 2011).

13. Bakare MO. Psychological disorders in Nigerian children and adolescents, and their peculiarities. In: Embracing Identity while Nurturing Diversity. 2007. http://iacapap.org/ wp-content/uploads/2011/05/Melbourne-Supplement-2007.pdf (accessed 9 November 2011).

14. Belfer ML. Child and adolescent mental disorders: the magnitude of the problem across the globe. J Child Psychol Psychiatry 2008;49(3):226-232.

15. Omigbodun O. Developing child mental health services in resource-poor countries. Int Rev Psychiatry 2008;20(3):225-235.

16. Kleintjes S, Lund C, Flisher AJ. MHAPP Research Programme Consortioum (2010): A situational analysis of child and adolescent mental health services in Ghana, Uganda, South Africa and Zambia. African Journal of Psychiatry 2010;13(2):132-139.

17. Njenga F. Autism in Africa: A challenge in the management of an important disorder http://www.vilanswebwinkel.nl/Site_LKNG/docs/PDF/IASSID\%202008/Njenga_autisme_ in_Afrika.pdf (accessed 2 March 2011).

18. Robinson EB, Munir K, Munafo MR, Hughes M, McCormick MC, Koenen KC. Stability of autistic traits in the general population: further evidence for a continuum of impairment. J Am Acad Child Adolesc Psychiatry 2011;50(4):376-384. 